ANE LEKUONAMARISCAL
Universidad del País Vasco anelekuona@gmail.com

\title{
La representación de las pintoras en la prensa del primer franquismo. El caso de Menchu Gal.
}


THE REPRESENTATION OF THE WOMEN PAINTERS IN THE PRESS OF THE FIRST FRANCOISM.

THE CASE OF MENCHU GAL.

\section{ABSTRACT}

The article analyses the representation of the painter Menchu Gal (1918-2008) in the press during early francoism (1939-1959). Through the analysis of different examples, we study what was the position of women in that artistic system, the importance that their representativeness had in this fact, as well as the different strategies developed, in this case by Gal, to negotiate the position of "woman artist".

\section{Keywords}

Woman artists, Early Francoism, Visuality, Gender Studies, Press.

\section{RESUMEN}

El artículo analiza la representación de la pintora Menchu Gal (1918-2008) en los medios de prensa del primer franquismo (1939-1959). A través del análisis de diferentes ejemplos se estudia cuál fue la posición de las mujeres en aquel sistema artístico, la importancia que tuvo la representabilidad de las mismas en este hecho, así como las diversas estrategias desarrolladas, en este caso por Gal, para negociar la posición de "mujer artista".

\section{Palabras Clave}

Mujeres artistas, primer franquismo, visualidad, estudio de género, prensa. 


\section{INTRODUCCIÓN}

Menchu Gal (1918-2008) fue una de las artistas plásticas que más reputación nacional alcanzó en los años cincuenta y sesenta del pasado siglo, siendo, entre otros galardones a destacar, la primera mujer en lograr el Premio Nacional de Pintura; sería en 1959. Sin embargo, el relato histórico que se fue conformando y afianzando a partir del tardofranquismo y el final de la Dictadura no se interesó por la producción de todas aquellas artistas que, como Gal, negociando su papel como mujeres y como artistas, realizaron una pintura cercana al naturalismo academicista.

Frente al largo recorrido que queda por trazar en el estudio de las artistas de la primera época del franquismo (1939-1959), en este caso nos interesa examinar cuál fue la imagen o la proyección social que se daba en los medios de estas ${ }^{1}$. Tal aproximación se inscribe en la línea de investigación de otros trabajos precedentes como los de Ma del Carmen Muñoz Ruiz (2003, 2006), Mónica Carabias Álvaro (2010), o María Rosón (2016), los cuales ponían de manifiesto la importancia que tuvo durante el franquismo la carga visual de las revistas, y, en general, de la prensa, en la construcción de los modelos femeninos. De esta forma, partiendo de las metodologías de los estudios visuales y feministas, planteamos el estudio de caso de Menchu Gal, ya que como pintora "excepcional" que alcanzó un gran reconocimiento público, contamos con suficientes medios materiales para poder realizar un análisis más exhaustivo en torno a esta cuestión. Los recursos empleados para ello han sido los reportajes que incluían mayor contenido visual y se ajustaban al intervalo de años entre las décadas 1940-1960; es decir, al periodo de años en el que la artista logró entrar y ser reconocida por el sistema del arte². Recuperar las palabras e imágenes que dieron a conocer la figura de Menchu Gal en su sociedad, como elementos constituyentes de la cultura visual y crítica de su tiempo, se convierten en una fuente reveladora a la hora de identificar los diferentes ideales, estereotipos y prejuicios que giraban en la época en torno a las artistas. Asimismo, estas huellas llevan a reflexionar sobre las diversas maneras de resistencia a las que recurrieron estas mujeres para negociar su lugar; sin duda, acciones y actitudes que no estuvieron exentas de riesgos y contradicciones. Con todo ello será evidente que, a pesar de lo represivo que fue el estado franquista respecto al ideario femenino, el campo visual no fue un espacio homogéneo, sino que, por el contrario, estuvo lleno de tensiones y discordancias (Rosón, 2016, p.13).

La figura de Menchu Gal es una referencia habitual en los estudios dedicados al arte de la posguerra ${ }^{3}$ o también en aquellos que han tratado de visibilizar a las mujeres artistas del pasado ${ }^{4}$. Sin embargo, mientras que otras artistas de su generación han sido objeto de nuevas investigaciones ${ }^{5}$, hasta la fecha, la mayor parte de la bibliografía dedicada a la pintora guipuzcoana surge de la esfera de la divulgación más que del mundo académico ${ }^{6}$. Una particularidad que ha propiciado que la artista siga siendo presentada, por lo general, como una pintora aislada en su excepcionalidad: aparentemente sin generar influencia, sin una línea genealógica al que pertenecer, sin ser conectada con su contexto social o sin ser contemplada por las nuevas miradas y lecturas que se han ido sumando a la disciplina de la historia del arte. Por ello, en esta ocasión, partimos de la premisa de Roziska Parker y Griselda Pollock (1981) cuando planteaban que realizar una investigación feminista dentro de la historia del arte supone aproximarnos a las condiciones históricas específicas en las que produjeron obra las mujeres, es decir, se tratara de estudiar la posición diferenciada que mantuvieron estas respecto a las estructuras patriarcales de la sociedad y del sistema artístico. De forma que, además de las condiciones 
sociales, económicas y políticas, otros asuntos como el poder representacional o el control social sobre los cuerpos -el campo de la biopolítica, en suma-, serán de vital importancia (Jones, 2003).

\section{Pintar bajo el nuevo orden franquista}

La figura de Menchu Gal se presenta como un caso interesante, entre otras cuestiones, porque aunque desarrollara la mayor parte de su carrera a partir de los años cuarenta, formó parte de aquella generación de mujeres que fueron instruidas en el ambiente artístico progresista de Madrid de los años treinta. Efectivamente, después de iniciar su formación artística en Irún, su ciudad de origen, y tras pasar un periodo de aprendizaje en París, gracias al apoyo y al soporte económico de su familia, la pintora pudo trasladarse a Madrid y estudiar en la Real Academia de Bellas Artes de San Fernando mientras se alojaba en la Residencia de Señoritas ${ }^{7}$. Ya en este periodo inicial, encontramos notas en la prensa que evidencian el reconocimiento que logró tener la pintora desde sus comienzos. Por ejemplo, el hecho de que la revista zaragozana Noroeste incluyera a la joven Gal junto a otras figuras femeninas relevantes como Maruja Mallo, Josefina de la Torre, Norah Borges o Ángeles Santos al dedicar un número a las escritoras y artistas modernas españolas del momento (Anónimo, 1935). No obstante, dos años después de haber llegado a Madrid se produjo el estallido de la Guerra Civil, lo que obligó a la pintora y su familia a refugiarse en el pueblo francés de Tardets, localidad en la que se establecieron hasta el final de la contienda ${ }^{8}$. A su regreso a principios de la década de los cuarenta, lidiando con las dificultades económicas de la posguerra, Menchu Gal pudo retomar su actividad pictórica y realizar ya en estos primeros años de vuelta exposiciones en Guipúzcoa y en Zaragoza. En el año 1943 la artista volvía a Madrid, ciudad donde se trasladaría definitivamente dos años más tarde y lograría desarrollar una exitosa carrera como pintora (Zubiaur, 2011, p.6).

Para contextualizar lo que suponía que una joven de veinticinco años como Menchu Gal se trasladara en solitario desde una ciudad provincial a la capital con la apuesta personal de profesionalizarse como pintora, es necesario recordar los cambios que se dieron en este corto rango de tiempo respecto a la posición social de las mujeres. Y es que, como ha sido estudiado, con la llegada del Régimen de Franco se rechazaron todos los avances introducidos en la Segunda República a favor de los derechos igualitarios -los cuales Gal pudo saborear en los círculos en los que participó en Madrid-. Así pues, la dictadura franquista trajo consigo un rígido sistema de género en el que el privilegio masculino se sostenía sobre la subalternidad femenina. Por ello, para el correcto funcionamiento de este modelo desigual fue imprescindible que se rechazara el prototipo de la mujer emancipada y moderna de los años treinta y se redefiniera un nuevo ideal femenino. De esta manera, la mujer franquista pasaba a ser aquella que, siguiendo su destino biológico, se dedicaba al cuidado; fundamentalmente al cuidado de la familia y el hogar, pero simbólicamente, también a la purificación moral y la recatolización de toda la sociedad española (Nash, 2015). Al servicio de la difusión de este nuevo arquetipo femenino trabajarían, por ende, diferentes agentes estatales como la legislación, la educación y el control moral o, como se estudia en este caso, el campo de la visualidad.

Por todo ello, de primeras, Menchu Gal y todas aquellas que aspiraron a profesionalizarse como artistas no se adecuaban a los estándares femeninos dictados por el Régimen. Sin embargo, al revisar el número de mujeres que participaron en el entorno artístico de a partir de los años cuarenta, advertimos que hubo una cantidad mayor de lo que cabría esperar en un principio; la 
mayoría de ellas, mujeres de origen burgués y afines al Régimen (Faxedas, Fontbona y Mayayo, 2019). Ahora bien, de todas estas, las que lograrían tener visibilidad en los medios y en las elites artísticas fueron pocas. Por ejemplo, en las Exposiciones Nacionales de Bellas Artes, el certamen más importante del momento, la proporción de mujeres exponentes únicamente llegaba al 10\% del total (Muñoz López, 2006). En esta reducida proporción es donde debe situarse el reconocimiento y la carrera profesional que logro tejer Gal.

\subsection{Leer las imágenes de la prensa}

El primer reportaje que analizamos fue publicado en la prensa guipuzcoana, a raíz de la exposición que celebró la pintora en el año 1942 en San Sebastián (De Ondarreta, 1942) (ver Fig. 1). El artículo titulado "Los cuadros de Menchita Gal” mostraba además del texto dos imágenes; la primera, un retrato de la pintora acorde al modelo fotográfico de la época, es decir, con el uso del primer plano y el perfil de tres cuartos. Pero, además, eran reconocibles diferentes referencias visuales de la época: la iluminación teatral, contrastada, y el maquillaje acentuado recordaban los retratos femeninos del mundo del cine y del espectáculo. Otras características, en cambio, como el tono oscuro general de la imagen, el peinado recogido y el rostro inexpresivo de la pintora, podrían vincularse al estilo que generalizó la Sección Femenina al retratar sus socias (Rosón, 2016, p.62). Así, la combinación de las diferentes características dotaba a la imagen de Gal la apariencia de ser una mujer fuerte y decidida, pero sin perder la necesaria apariencia femenina. Junto a esta fotografía se encontraba la imagen de una obra de la pintora. Con el pie de foto "Retrato de Menchu Gal" se mostraba un cuadro donde figuraba una mujer joven, acorde a los estándares de belleza; una señorita que, arreglada para un evento social, era captada mirándose en el espejo de su tocador, lo que podría ser el retrato de los últimos instantes privados de la joven antes de salir al foco social. En este caso, lo que interesa para el análisis es que siendo Menchu Gal una pintora que desde sus inicios destacó principalmente por sus obras paisajísticas, para ilustrar el reportaje se seleccionara este retrato femenino. Pese a desconocer si realmente se trataba de un autorretrato o una representación femenina, a ojos del lector o lectora la imagen actuaría de la misma manera que si lo fuera, esto es, ambas imágenes -la de la artista y la obra- pasan a conformar la representación visual de la autora a partes iguales.

Efectivamente, este ejemplo no fue un caso aislado, sino al contrario, diferentes reportajes datados en estos mismos años muestran que el recurso de presentar a las artistas a través de sus autorretratos o cuadros de figuras femeninas fue algo habitual en los medios de prensa (ver Fig. $2)^{9}$. Este hecho plantea la reflexión de si las artistas al realizar este tipo de escenas, más o menos conscientemente, estarían tejiendo una identidad pública. En algunos casos, como muestran diferentes investigaciones feministas en torno al uso del autorretrato en mujeres artistas de la historia, esta categoría posibilitó el espacio para que estas pudieran reelaborar una identidad propia, subjetiva y liberada de la mirada normativa ${ }^{10}$. Sin embargo, en muchos otros casos, las autorrepresentaciones de las artistas reflejaban la colonización visual que mencionamos, lo que Luce Irigaray (2003) definía como "la mirada alienada por la subjetividad masculina". En estos casos, al proyectar y proyectarse a través de las figuras femeninas, las artistas se estarían presentando en público acorde a lo socialmente aceptado como imagen de una mujer exitosa, es decir, ajustándose a las conductas de género esperadas de ellas y mostrando un cuerpo bello y sexualmente deseable. En definitiva, el ejemplo recuerda cómo la mirada masculina estaría 
interviniendo en los diferentes niveles implicados: desde el uso de este recurso por parte de los medios de comunicación, la interpretación que el leyente hacía del reportaje, hasta en la propia producción artística de las pintoras.

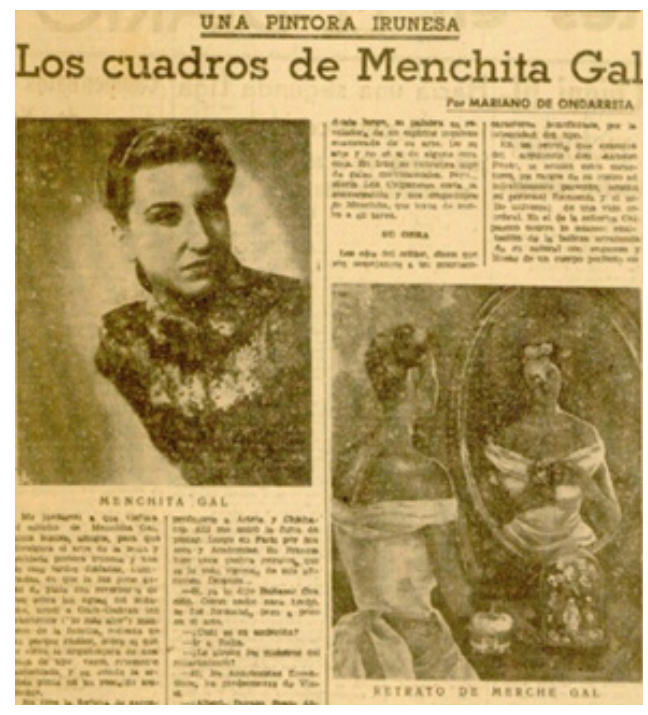

Figura 1. De Ondarreta, M. (7 de agosto de 1942). Diario Vasco, p.6. Centro de Documentación Eusko Ikaskuntza.

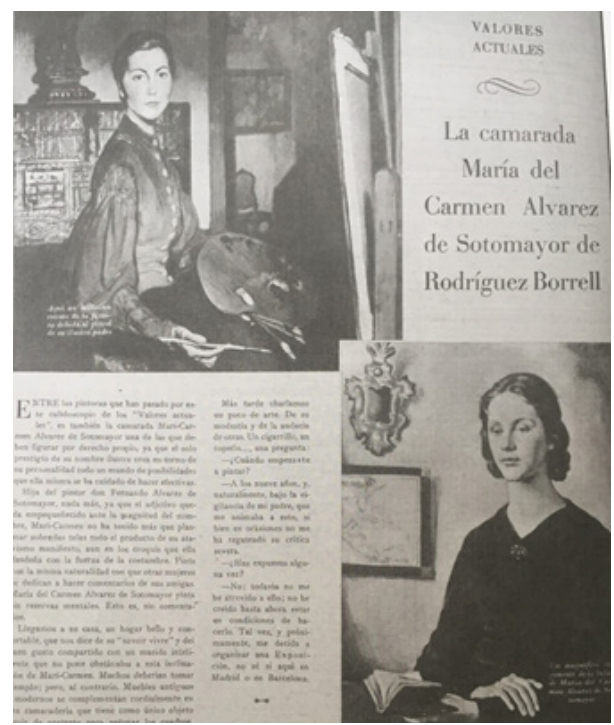

Figura 2. Benson, B. (7 de marzo de 1945). La camarada María del Carmen Álvarez de Sotomayor de Rodríguez Borrell. Medina, p.7. Biblioteca Nacional de España.

A continuación, pasamos a comentar el extenso reportaje que la revista ilustrada Fotos realizó a la pintora vasca en 1948 (Pombo Angulo, 1948), el cual resulta esclarecedor por condensar algunos de los estereotipos que se asociaban a la figura de la mujer artista. Así comenzaba:

\footnotetext{
Que una mujer pinte no tiene nada de extraño. En realidad, la mujer, completando eso que llaman "su educación", pasa del bordado a la pintura con idéntico criterio y, la mayor parte de las veces, con parecida técnica. De este modo las paredes familiares se cubren con las obras de la niña de la casa, que insiste, sospechosamente, en los floreros y los bodegones. No, lo sorprendente no es que una mujer pinte, sino que pinte bien para nosotros (Pombo Angulo, 1948).
}

Efectivamente, al igual que la costura o el piano, la práctica pictórica había sido asumida desde el XIX como una actividad adecuada para el género femenino, propia de la educación que recibían estas en su etapa de solteras. No obstante, esta debería realizarse en un plano imitativo y reproducir los temas tradicionalmente asociados a la feminidad como, por ejemplo, los bodegones, los retratos, las escenas florales o los paisajes (Tejeda, 2013). Por lo tanto, de primeras, la práctica y el tipo de producción de Menchu Gal encajaba en lo socialmente esperado de una artista plástica, lo que resultaba sorprendente -así lo afirmaba el periodistaera su capacidad o talento para sobresalir aun realizando tal arte femenino. El artículo seguía: 
Sin embargo, a las obras de Menchu Gal no puede negárseles interés. Esta muchacha de perfil vasco, brazos fuertes y opiniones directas, que nunca cuida de embozar, tiene, además, un criterio original sobre la pintura y los pintores; un criterio original en una mujer, porque, en muchos casos, opina como un hombre. [...] -¿¿ué te hubiera gustado ser en la vida, Menchu? -Pintora - ¿Y qué te hubiera gustado no ser? -Maestra. [...] Realmente, Menchu Gal hubiera hecho una extraña maestra de escuela. Ahora viste una zamarra vasca [...] fuma sin cesar tabaco americano... Resultaría difícil aprender de esta muchacha (Pombo Angulo, 1948).

En efecto, esta descripción sobre la actitud y la apariencia de la pintora retrataba una imagen masculinizada de la pintora, siendo por ello juzgada por el periodista y, por consiguiente, por el público lector. Sin embargo, el texto se acompañaba con la siguiente fotografía (ver Fig. 3). Una imagen en la que, a través del encuadre horizontal y una luz envolvente se mostraba una pintora absorta en su actividad, en su espacio íntimo, el taller; una mujer con la mirada baja, cuerpo erguido pero ensimismado, el pelo recogido y una vestimenta sobria. Es decir, la imagen podría entenderse como una nueva construcción visual de la mujer artista, donde el estudio pasaba a identificarse como un espacio aprobado para la feminidad. Esto es, la privacidad del taller, separado del ámbito doméstico, se presentaba como aquella "habitación propia" o lugar fundamental donde, a priori, las mujeres podían aislarse y "crecer" como artistas. Asimismo, la actitud trabajadora, pero a su vez sosegada, no planteaba una amenaza a las conductas de género aprobadas en la sociedad. Este tipo de representaciones se repetía en la proyección de otras pintoras de la época ${ }^{11}$, pero también en las representaciones pictóricas de las mismas. Por ejemplo, el autorretrato de Adela Tejero -más conocida como Delhy- (ver Fig. 4), compañera de Gal en la "Escuela de Madrid", proponía esta misma visión de la mujer artista; esto es, un ideal de la artista como mujer moderna, socialmente reconocida y realizada, pero que su espacio de actuación seguía siendo la esfera privada: su estudio.

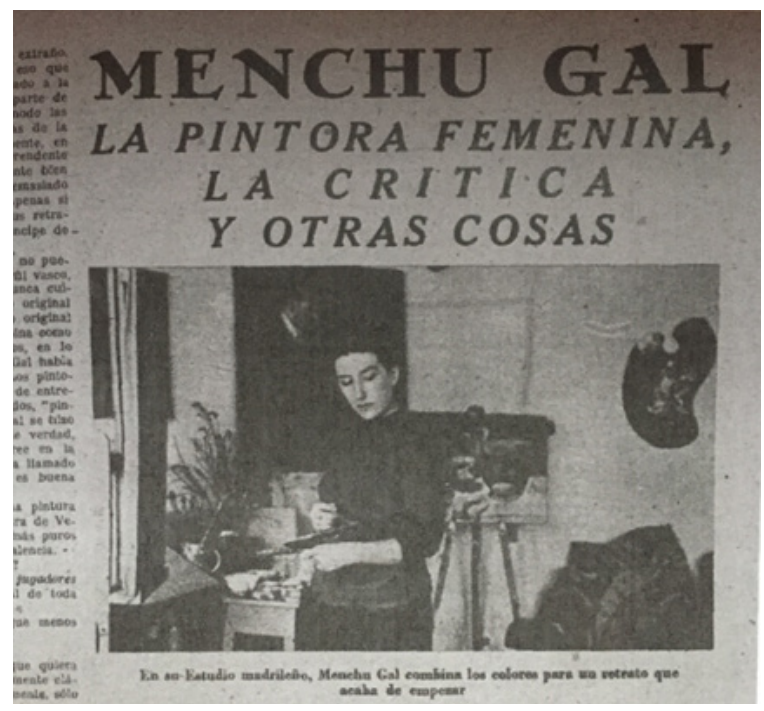

Figura 3. Pombo Angulo, M. (19 de junio de 1948). Menchu Gal. La pintora femenina, la crítica y otras cosas. Fotos, p.13. Biblioteca Nacional de España. 
De esta manera, volviendo al ejemplo, la descripción desaprobada que el texto hacía de Gal, mostrándola como una mujer "poco femenina" quedaba compensada o suavizada por medio del apoyo visual. Más tarde profundizaremos sobre esta idea, pero resulta significativo que, ya en fechas tan tempranas, se diera una de las características que se mantendría a lo largo de estos años en la representación pública de Menchu Gal -habitual también en otras artistas reconocidas-: la continua negociación y diálogo entre los rasgos masculinos y femeninos. Como último punto a destacar del reportaje encontramos esta reflexión acerca de la opinión general del momento en torno a la capacidad artística de las mujeres:

-Oye Menchu: ¿la mujer puede llegar a conseguir algo definitivo en pintura? -iNaturalmente! ¿Por qué va a ser la pintura exclusiva masculina? Apenas se establezca -y ya está establecida- una tradición de pintoras, se demostrará que la mujer puede pintar tan bien, de acuerdo con su sensibilidad como el sexo contrario. Lo que más sucede es que los hombres han madrugado más que ellas. [...] Uno, la verdad, no acaba de ver la posible relación entre la precocidad en el abandono del lecho y la manipulación del óleo, pero debe existir, Menchu Gal prosigue: -Ahí tienes, por ejemplo, el caso de Suzane Valadón. Suzane, en primer lugar, es la madre de Utrillo, gloría que ningún hombre hubiera podido alcanzar. [...] Uno empieza a preocuparse un poco. -En segundo, pinta maravillosamente. Tienes también otras pintoras completas, como Berthe Morisot, Marie Laurencin, y en España, Margarita Fran y Carmen Legísima. La mujer puede hacer tanto o más que el hombre (Pombo Angulo, 1948).

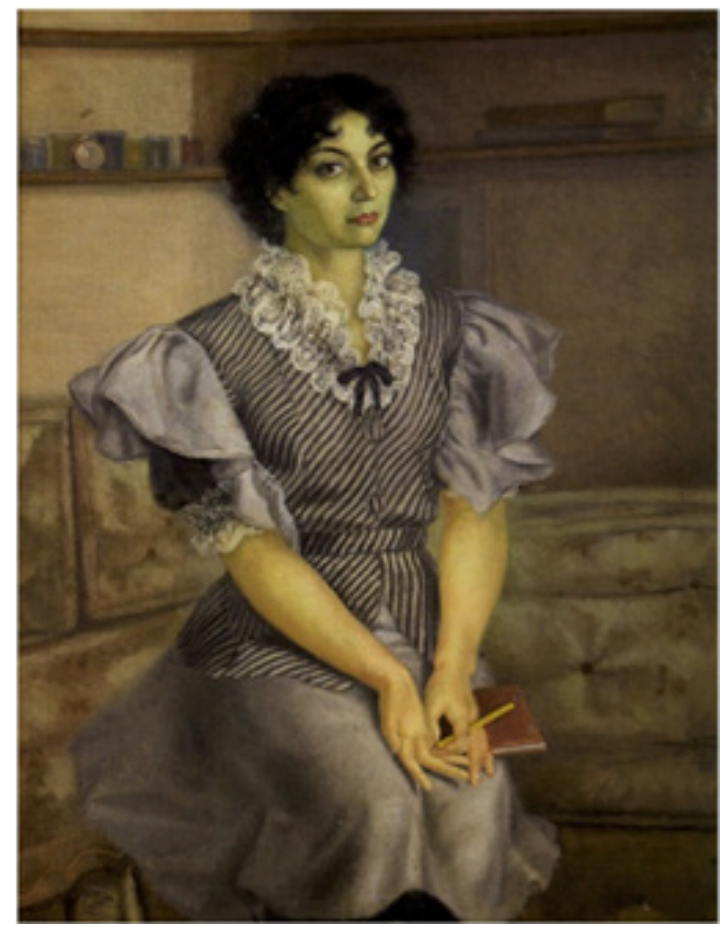

Figura 4. Delhy Tejero. 1945. Autorretrato. Colección Javier Vila Tejero. 
De este fragmento de la entrevista cabría apuntar algunas ideas. En primer lugar, que el testimonio, el cual se repetiría en diferentes entrevistas ${ }^{12}$, refuerza la hipótesis de que Menchu Gal afrontó su carrera profesional a través de una mirada emancipadora, pues trató de demostrar que, como mujer, estaba dotada de las mismas capacidades creativas que sus colegas masculinos. Ahora bien, la manera en que la artista justificaba esta desigualdad era perpetuando los estereotipos machistas enraizados de su sociedad, es decir, replicando la idea de que si las mujeres no alcanzaban el éxito social era porque, al contrario que los hombres, no tenían predisposición hacia la disciplina y la superación personal. Al reafirmar estos tópicos, Menchu Gal se posicionaba en la estructura social como mujer que se agenciaba de las cualidades de los hombres, aquellas mismas que la dotaban de distinción. Como última idea a comentar del artículo, y teniendo en cuenta la fecha en la que da se la entrevista, destacar el énfasis que ponía la pintora al argumentar que sí que habían existido y existían destacadas pintoras en la historia y en el mundo del arte del momento. A su vez, el hecho de que Gal conociera estos nombres y replicara la visibilidad de sus legados demuestra que, de alguna manera, estas antepasadas habrían funcionado a modo de referentes para ella. Por último, es relevante que la respuesta que daba la pintora correspondía a la misma estrategia de resistencia que defenderían a partir de los años setenta las primeras historiadoras del arte y artistas feministas; esto es, responder a la falta de nombre femeninos dentro de la historia del arte occidental replicando y demostrando que sí las hubo (Mayayo, 2003, p.25).

Si las anteriores fotografías analizadas habrían sido tomadas en una sesión fotográfica premeditada y elaborada expresamente para aquellos reportajes, pasamos ahora a analizar una imagen captada en un contexto completamente diferente (Anónimo, 1951) (ver Fig. 5). Esta instantánea fue tomada en el año 1951 con motivo de la inauguración de la exposición colectiva que la "Escuela de Madrid" realizó en la galería Biosca de Madrid"13. Y es que un hecho significativo en la carrera profesional de Menchu Gal -por no ser lo habitual entre las artistas del momento- es que fue miembro de este colectivo reconocido de paisajistas. Así, al observar la imagen es evidente que, a diferencia de la anterior fotografía, esta habría sido tomada en el transcurso del evento social, en la rapidez y el desenfado que caracterizaría tal ambiente. Por ello, el documento pone a la vista y plantea otras cuestiones acerca de la manera en que la pintora se mostraría en aquel ambiente artístico masculino, así como la forma en que dialogaría y negociaría su lugar desde esa posición.

A primera vista, vemos que, para la composición de la imagen grupal, el lugar designado a la pintora, como anomalía que representaba ${ }^{14}$, era el centro. Una centralidad que se acentuaba con la altura y la vestimenta de gama más clara que llevaba la pintora en contraste con los atuendos oscuros de los demás artistas. Con ello, la disposición visual vendría a repetir un tópico generalizado en torno a las artistas, esto es, que la razón por la cual estas habían logrado ser reconocidas y alabadas por las elites del mundo del arte, era debido al apoyo, promoción o favoritismo que habían recibido por parte de sus colegas o parejas sentimentales; en el caso de Gal, esa figura de mentor la encarnó Benjamín Palencia ${ }^{15}$. De esta manera, como señalaba Whitney Chadwick, las artistas pasaban a ser el "descubrimiento", el object trouvé de aquellos hombres y, por tanto, el reconocimiento recaía más en los propios descubridores que en lo descubierto (1985, p.103). Al igual, si reparamos la expresión corporal de la pintora, percibimos que aquella posición central que le había sido dotado, aquel lugar privilegiado de representar la excepción, en realidad se correspondía a un espacio hostil, incómodo y lleno de riesgos. Dicho en otros términos, la disposición corporal que presentaba Menchu Gal vendría a reflejar aquello que planteaba la teoría de la performatividad de Judith Butler, es decir, que los discursos del 
poder logran agenciarse de los cuerpos que habitan sus realidades (2002, p.19).

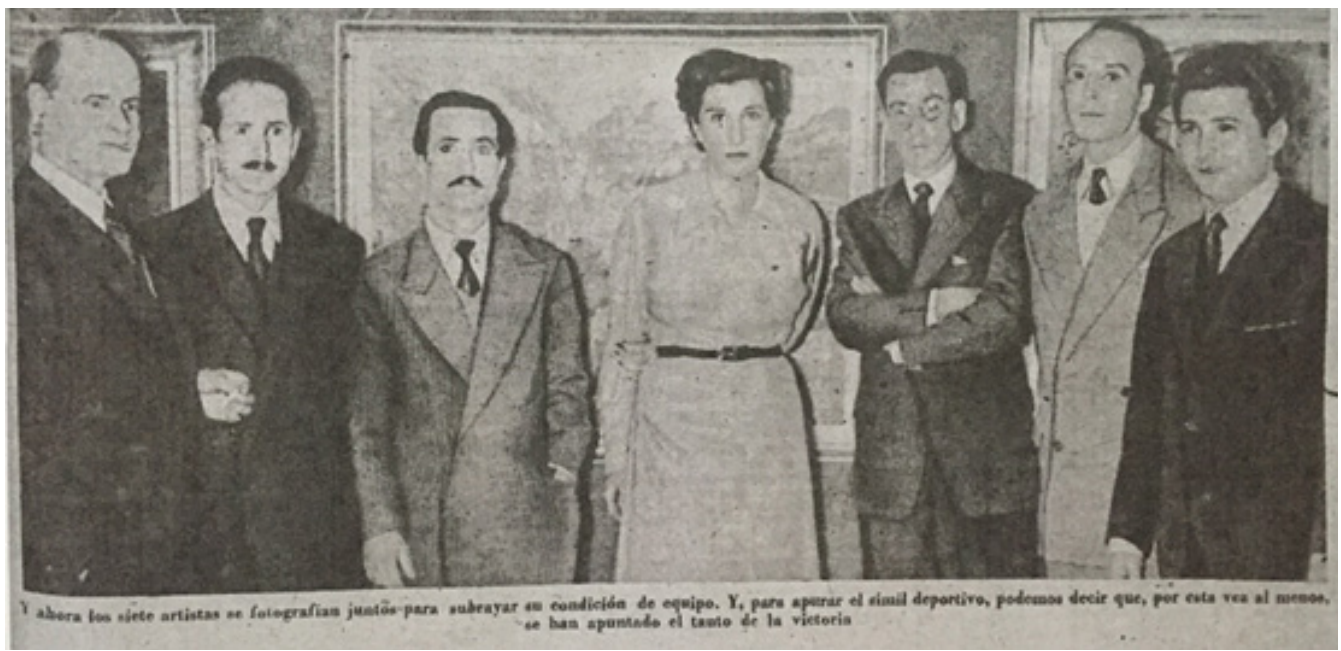

Figura 5. Anónimo (17 de marzo de 1951). Muestra de la joven escuela madrileña. Fotos, p.40. Biblioteca Nacional de España.

El cuarto ejemplo data del año 1954 y pertenece a un reportaje publicado en la revista deportiva Marca (Sampelayo, 1954) (ver Fig. 6). En él se preguntaba a algunas mujeres destacadas de la sociedad española cuál era su opinión en torno a la práctica deportiva masculina. El hecho de introducir a Gal en este tipo de magacines dirigidos al público popular masculino revela que la pintora tuvo una posición célebre en la sociedad y fue presentada en los medios más conocidos como una referente femenina. En primer lugar, los ejes diagonales que conformaban la página respondían a los estándares de gusto del momento, los cuales trataban de dar dinamismo y agilizar la lectura (Rosón, 2016, pp.64-66). Pero respecto a la fotografía de la pintora, en el ángulo alto de la parte derecha, vemos que Menchu Gal era retratada al estilo de las actrices de Hollywood, acorde a los estándares de belleza femeninos y glamurosos de los años cincuenta. Así es, sobre el fondo liso del estudio, el primer plano del rostro lograba resaltar el recogido voluminoso, el marcado maquillaje y la mirada directa de la pintora, rasgos que dotaban a la artista esa apariencia de feminidad moderna. Además, la iluminación, posteriormente tratada en el estudio, enfatizaba estas cualidades.

Por todo ello, y teniendo en cuenta el medio en el que se publicaba esta imagen, percibimos que aunque vinieran a representar mujeres destacadas de la sociedad, la forma en que se retrataba aquí a Menchu Gal -y a las demás mujeres que compartían página- era a través del estereotipo de la mujer inocente o "tontita" a la cual se le preguntaba sobre cuestiones que, como el deporte, nada tenían que ver con su universo femenino ${ }^{16}$. Ciertamente, lo placentero o entretenido del artículo radicaba en ello, en que, bajo esa apariencia inocente, el colectivo femenino tentara o "pecara" traspasando al imaginario del otro masculino. No obstante, para el correcto funcionamiento de este mecanismo resultaba imprescindible que se mantuviera la clara distinción entre la dicotomía hombre-mujer, de ahí la extrema feminización que 
encontramos en el retrato de Menchu Gal. En segundo lugar, el hecho de introducir a Gal como referente femenino presenta el dilema de si la figura y la profesión de las artistas se veía y se proyectaba en la sociedad como algo deseable o si, al contrario, constituía una trasgresión de los límites femeninos y, por tanto, suponía algo reprobable.

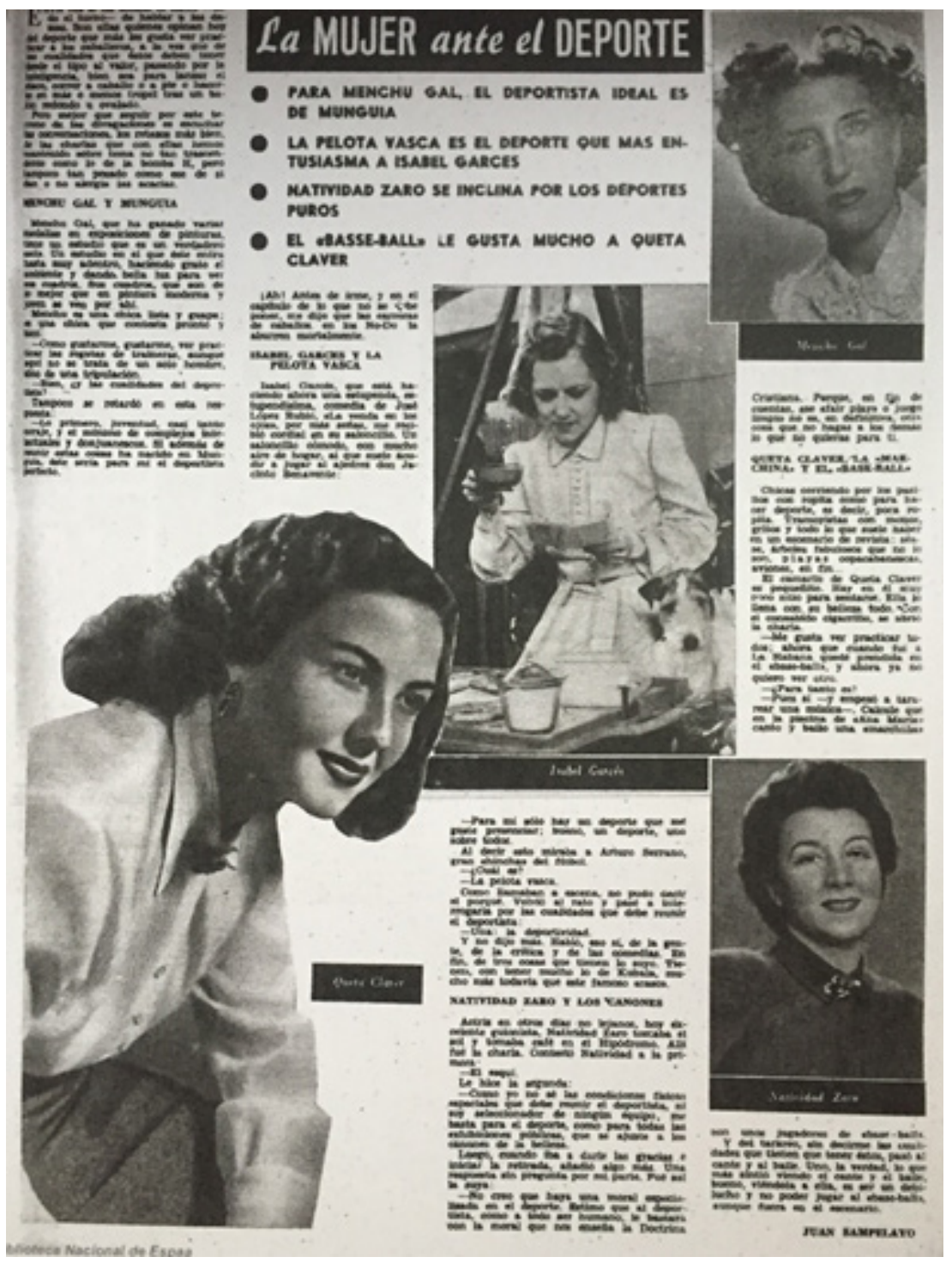

Figura 6. Sampelayo, J. (20 de abril de 1954). La mujer ante el deporte. Marca. Semanario gráfico de los deportes, p.15.

Biblioteca Nacional de España. 
Como contraposición al anterior ejemplo, el año 1957 se publicaba el siguiente extenso reportaje en la revista La Nueva España (Báez, 1957) (ver Fig. 7). Dos páginas con extenso contenido visual donde, a simple vista, era evidente la manera tan diferente en la que se retrataba la pintora. El fotógrafo, a través de diferentes ángulos y planos picados captaba a Menchu Gal en acción, mostrando su movimiento corporal: hablando, mirando fijamente, gesticulando o fumando. Así pues, a pesar de que la apariencia física de la pintora respondiera a lo consesuadamente reconocido como una mujer femenina, diferentes elementos integrados en el lenguaje gestual dotaban de masculinidad a la apariencia de Gal. Por otra parte, en el texto del artículo se encontraban comentarios repetidos anteriormente, como el de destacar el físico "fuerte" de la pintora como arquetipo de la "mujer vasca"17 o la pregunta acerca de si las mujeres podían "llegar a lo genial"18. Otra de las preguntas planteadas era si la pintura le remuneraba económicamente, lo que muestra la opinión generalizada de la imposibilidad de que incluso las artistas más reconocidas del momento pudieran profesionalizarse a través de su arte. Menchu Gal respondía poder vivir de ello.

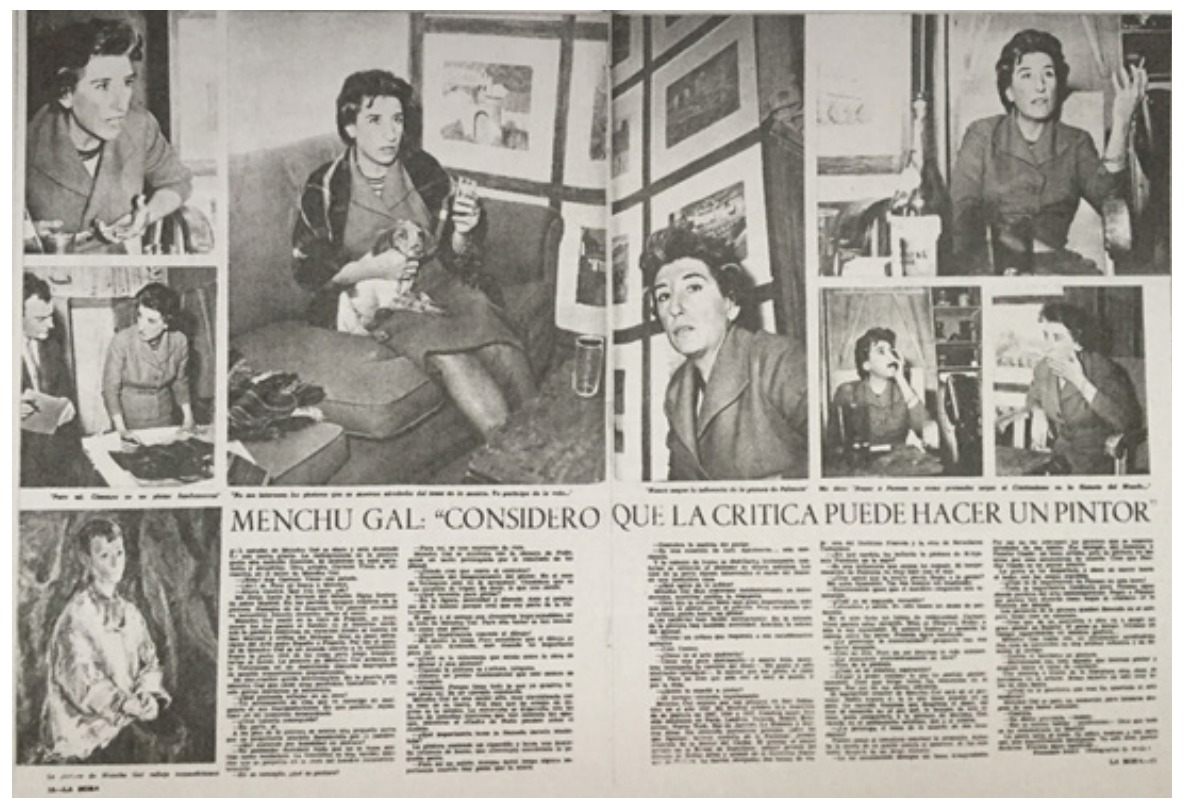

Figura 7. Báez, F. (9 de mayo de 1957). Menchu Gal: "considero que la crítica puede hacer un pintor". La Hora, p.14. Biblioteca Nacional de España. 
Los diferentes casos analizados han servido para evidenciar cómo respecto a la identidad de género, la proyección que se hizo de la pintora en la prensa del primer franquismo fue muy heterogénea. Pasamos ahora a reflexionar sobre este fenómeno. En primer lugar, aclarar que pese a reconocer que detrás de cada imagen se encontraría la mirada subjetiva de quien captó la instantánea, en este caso al tratarse de imágenes realizadas por fotógrafos anónimos con el único fin de ser mostradas en la presa, y recordando las fuertes medidas de control y censura que caracterizaron la época, nos aproximamos a estudiarlas como ejemplos de la cultura visual oficial del primer franquismo; es decir, como obras colectivas realizadas a partir de la mirada de quien tenía autoridad para imponerlo.

De esta forma, toda representación de Menchu Gal en los medios estaría sujeta a esa premisa y, de hecho, algunas fotografías ejemplificaban a la perfección la imagen femenina que cabría esperar de la visualidad canónica de estos años. Ese sería el caso de los retratos que más elaboración habrían requerido en su producción -por el tiempo de preparación escénica, lumínica y de vestimenta que exigían-. Por ejemplo, en el primer y segundo caso, la pintora se presentaba acorde a los dos estereotipos femeninos que caracterizaron cada periodo: la primera mostrando un ideal femenino más duro o serio y la segunda, asemejada al ideal de mujer doméstica y sumisa. Por su parte, el retrato del cuarto ejemplo, siendo publicado nueve años más tarde, se ligaba al ideal de belleza femenina de la época, con fuerte influencia del imaginario hollywoodiense de la década. No obstante, en diálogo con esta proyección femenina acorde a la norma, en la mayoría de las descripciones textuales que se daban en los medios de comunicación acerca de Gal, como decíamos, se insistía en la actitud o en los rasgos "poco femeninos" de la artista; lo que en términos visuales estaría más acorde al último ejemplo. De hecho, esta constante negociación entre los rasgos masculinos y femeninos pasaba a ser la característica principal de la imagen pública de Menchu Gal en los años del primer franquismo. Luego, ¿cómo explicar que en algunos casos se criticara su falta de decoro y en otras se mostrara a la pintora como referente femenino?

En efecto, en el contexto de una época caracterizada por el retorno de los valores patriarcales más absolutos, los diferentes ejemplos que exageraban y desacreditaban el atrevimiento o "perversión" de Menchu Gal se convertían en reflejo de los diferentes mecanismos interiorizados en la sociedad para tratar de reconducir las inapropiadas conductas de género. Además de las críticas explícitas, el caso que trataba de contrarrestar la carga masculina a través de la proyección visual es un claro ejemplo de este procedimiento. Ahora bien, decíamos que, incluso representando esta imagen masculinizada, la prensa de la época también presentó a Menchu Gal como referente o modelo femenino ${ }^{19}$. La contradicción que aquello revelaba tiene que ser relacionada con el hecho de que, en los medios visuales del primer franquismo, la figura de la mujer fuerte y activa fue mucho más común de lo que cabría pensar en un principio. Así lo demostraba Jo Labanyi (2002) en su análisis sobre el papel de las mujeres en la industria cinematográfica o María Rosón (2012) cuando estudiaba la construcción visual de la Sección Femenina y sus mandos. De modo que Menchu Gal, en su papel de pintora reconocida, vendría a encajar en esta misma categoría femenina. Muestra de esta analogía podría ser la siguiente nota en prensa, publicada en 1961 en La Nueva España: 
Son llamadas las mujeres más célebres de nuestras mujeres y responden todas muy unánimemente, desde Pilar Primo de Rivera, tan responsabilizada con su Sección Femenina, obra totalmente suya, hasta Menchu Gal, que es de Irún. En la encuesta desfilan la mayoría de las mujeres importantes de la vida española en el momento actual (Alberti, 1961).

Una lectura posible de este modelo de la mujer masculinizada podría hilarse con la lectura que hacía Estrella de Diego (2018/1992) en torno a la figura del andrógino, es decir, la figura que logra la totalidad o la plenitud de ambos sexos. Así, cuando una mujer se apropiaba de los elementos asociados a la masculinidad, es decir, al poder, estaría tratando de adueñarse de aquellos privilegios que a las subjetividades femeninas les eran excluidas. Recuperando los planteamientos de Butler, de Diego planteaba el debate en torno a la posibilidad de pensar en la androginia como vía para equilibrar la dicotomía social de lo femenino y lo masculino, esto es, como nuevo modelo de bienestar social (p.75). En este caso, podría decirse que, gracias a esta transgresión o negociación "andrógina", Menchu Gal logró desarrollar una carrera profesional anómala entre las mujeres de su sociedad y alcanzar privilegios asociados al universo masculino. No obstante, los riesgos y consecuencias ocasionadas por ello, como comentamos a continuación, no fueron pocas.

\subsection{Transgredir desde lo personal}

El siguiente apartado trata de aproximarse a este mismo material de prensa -también a sus ausencias, a lo que no fue mostrado en público- tomándolas como testigos para llegar a conocer las diferentes estrategias y formas de negociación que desarrolló la pintora para situarse en dicho sistema. En primer lugar, respecto a su proyección social, las fotografías revelan cómo en la forma de vestir y arreglarse, la artista se mostró acorde a la moda femenina de cada época. La trasgresión que se reprobaba en la figura de Gal estaría, por tanto, relacionada con otro ámbito, con su conducta y sus acciones, en concreto: en apostar por su arte, en profesionalizarse e independizarse económicamente, o en otras palabras, en oponerse al ideal femenino del "ángel del hogar" y vivir acorde a otros estándares alejados del papel de madre y esposa perfecta. Por lo tanto, la negociación se encontraba en ese margen de posibilidad: en realizar un arte "femenino" que la dotara de aceptación social, pero transgredir en la forma de llevar a cabo esta práctica. El hecho de que se relacionara y formara parte del colectivo "Escuela de Madrid", por ejemplo, así lo evidenciaba, también los diferentes testimonios en los que expresaba su fuerte compromiso hacia la pintura ${ }^{20}$, su reivindicación a la capacidad artística femenina, el desinterés en realizar profesiones "más femeninas" o su forma de vida personal; ya que, en un momento donde la soltería no era una opción para una mujer respetada, no se casó ni tuvo hijos. De hecho, Isabel Tejeda (2013) destacaba el recelo con el que Gal respaldó su vida personal, lo que podría interpretarse como otra forma de resistencia para proteger su posición. De características diferentes pero un fenómeno similar al de Marisa Roësset (CapdevilaArgüelles, 2013, pp.115-139).

Asimismo, esta negociación pasaba también por su producción artística. Decíamos antes que la obra de Menchu Gal encajaba en lo socialmente aprobado para una pintora de la época: realizaba cuadros al óleo de retratos -femeninos en su mayoría-, escenas florales y, principalmente, paisajes. No obstante, la idea de que este tipo de obras no presentaban ninguna lectura ideologizada puede ser revisada. Ejemplos como, el empleo del paisaje como 
medio de expresión, el estrecho lazo que mantuvo la pintora con Benjamín Palencia desde su llegada a Madrid o que junto a otros compañeros formara el colectivo que hacía referencia al término "escuela", evidenciaba que la aproximación artística de la pintora irunesa, al igual que la propia "Escuela de Madrid", se enlazaba con el espíritu y los preceptos artísticos de la previa Escuela de Vallecas (Cabañas, 1996, pp.61-62). No obstante, la consideración que tuvo el género del paisaje en la pintura de los años cuarenta y cincuenta por mitificar la tradición rural como fuente de virtudes para la nueva época política (Jiménez Blanco, 2016) hizo que la fórmula de Gal fuera entendida en estos términos y que, como representante del colectivo, se beneficiara de las diferentes plataformas internacionales que ofreció el sistema artístico en esos años ${ }^{21}$.

\section{CONCLUSIONES}

Los reportajes y fotografías de prensa, como huellas materiales de aquella sociedad, han servido para reflexionar sobre la imagen pública y social de la pintora Menchu Gal en el primer franquismo. Así, en contra de lo que cabría esperar de la imagen canónica de la mujer franquita, los materiales revelan identidades ambiguas. Asimismo, esta heterogeneidad evidencia los diferentes estereotipos, contradicciones y mecanismos que se generaron en la sociedad en relación a la construcción de identidades de género. Pero también nos hablan del margen o espacio de posibilidad que tuvieron figuras como Menchu Gal en la negociación de su posición; es decir, entre representar el modelo femenino aceptado socialmente, y transgredir esos límites a través de sus acciones y prácticas. Al igual, cabe recordar que aquello que hemos denominado "margen de negociación" resultaba una posición arriesgada y cambiante. Complicado por tener que asumir riesgos personales, como el hecho de abrirse camino en un mundo de hombres o, recibir críticas machistas por actuar y vivir fuera de las normas femeninas tradicionales. En entrevistas realizadas a posteriori fue usual, por ejemplo, que la artista recalcaba lo duro y solitario que fue su regreso a Madrid en los años cuarenta: "Fue muy dura en Madrid, muy dura. Porque yo iba de provincias, yo era, pues eso, una provinciana y he luchado con hombres. Y los hombres son muy hombres ellos" (Fundación Menchu Gal, 2013). Riesgos asumidos que deben ser relacionados con la educación y las oportunidades materiales y simbólicas que disfrutó la artista desde joven, así como la propia actitud de reivindicación que demostró desde el plano personal. Al igual, decíamos que se trataba de un rango de acción cambiante, pues a medida que la artista se consagró en el sistema del arte, también a la par de los cambios que se comenzaron a percibir a favor de los derechos de las mujeres (Tejeda, 2013), la manera en que se proyectaría en los medios la figura de Gal sería muy diferente a partir de 1960. Efectivamente, desde esta fecha en adelante la manera más usual de representar visualmente a la artista fue en solitario y acompañada de alguno de sus obras (ver Fig. 8). Al igual, las críticas escritas disminuyeron las referencias a los rasgos masculinos y femeninos, aunque no desaparecieron ${ }^{22}$.

Para terminar, resulta necesario poner el foco en el relato historiográfico, pues siendo una de las artistas más destacadas y consideradas de la década de los cincuenta (Muñoz López, 2003, p.253), su papel dentro de la narrativa histórica no se ajusta a este hecho. La razón que explicaría este fenómeno, decíamos al inicio, debe ser relacionada con la forma en que se escribió y se legitimó a partir del tardofranquismo y el final de la Dictadura la historia del arte del primer franquismo. De manera resumida, este discurso siguió alimentando la idea originada a partir de la I Bienal Hispano-Americana de Arte, celebrada en 1951, de entender el paso de la figuración a la abstracción como un paso evolutivo hacia la modernidad (Díaz Sánchez, 2013, 
pp.283-325). Al igual, se rescatarían y favorecerían aquellas propuestas artísticas que pudieron ser interpretadas como un arte de resistencia o antifranquista y, en el caso del País Vasco, en el intento de elaborar una narrativa histórica en clave nacionalista, a este último criterio se añadía la predilección por las propuestas que manifestaron una preocupación por la cultura vasca (Lekuona Mariscal, 2020). De modo que los criterios de calidad no favorecieron otras propuestas como la de Menchu Gal y muchas otras que, ajustándose a sus opciones más limitadas, realizaron, por lo general, un arte etiquetado como "naturalismo academicista" (Rosón, 2016, p.302). En el caso específico de Gal, el carácter machista de esta escritura se evidenciaba, por ejemplo, en que mientras algunos historiadores interpretaron la Escuela de Madrid como un intento colectivo por retratar a través de los áridos paisajes la sociedad de posguerra, en los escritos que analizaban individualmente a la artista nunca se trascendía esa lectura sociológica (García Soriano, 2009). Y lo mismo ocurría con la narrativa nacionalista del País Vasco donde, a pesar de que la artista recalcara en varias ocasiones su raíz vasca ${ }^{23}$, sus obras fueron entendidas como anticuadas y desatendidas de la realidad social del País Vasco. Ella misma respondía de esta manera a la pregunta de cómo creía ser vista en su ciudad:

Pues nada, como a una señorita que le dio por pintar. En Irún, en San Sebastián, y en todo el País Vasco les ha costado mucho tragarme a mí. En Madrid, en cambio, he tenido muchísima consideración. Pero aquí, poca cosa, incluso después cuando ya había estado en la Escuela de Madrid, ya me había llevado la Segunda medalla, ya había tenido premios importantes, como el nacional de Bellas Artes. Aquí me han hecho cosas muy feas (Aguiriano, 2001, p.25).

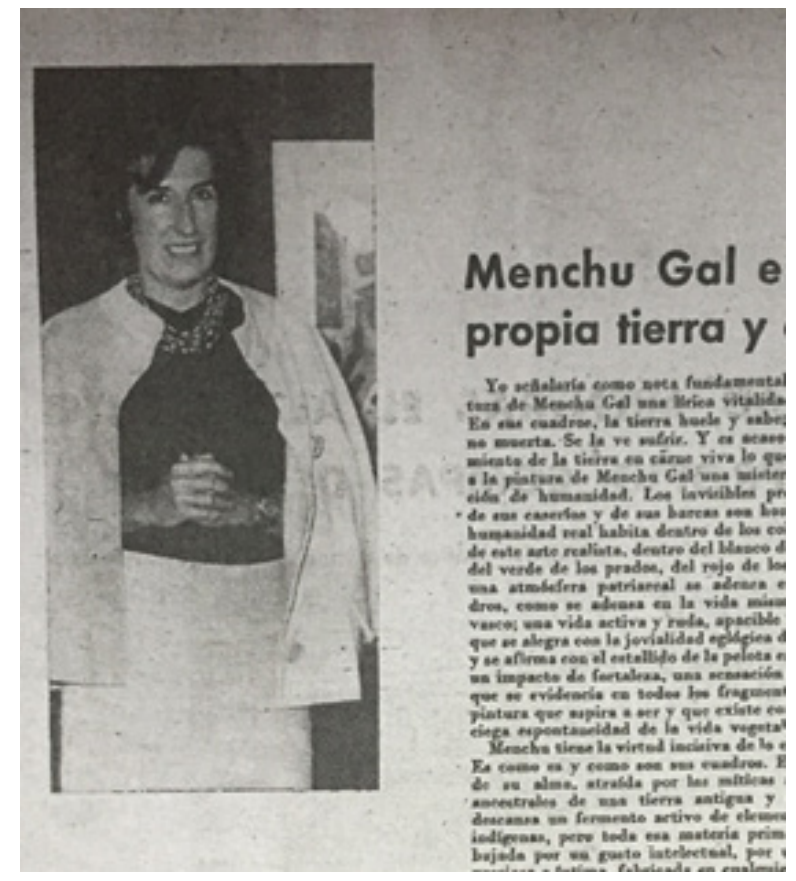

Figura 8. Villacorta, J. C. (29 de abril de 1961). Fotos, p.8.. Biblioteca Nacional de España. 
De modo que además de transgredir los obstáculos machistas de su época ${ }^{24}$, la memoria de las artistas que consiguieron "hacerse hueco" se enfrentaba a los criterios androcéntricos de la historiografía. Una de las consecuencias directas de este olvido sistemático por toda producción asumida como "arte femenino, burgués y franquista" sería, por ejemplo, que las siguientes generaciones de mujeres artistas, como señalaba Patricia Mayayo (2009), carecieran de referentes femeninas nacionales y locales. Un hecho significativo, ya que, con anterioridad a la legitimación de este relato histórico, encontramos diferentes iniciativas generadas por mujeres donde la pintora fue presentada a modo de mentora o referente para la siguiente generación de mujeres artistas. Ello ocurría, por ejemplo, en el VII Salón Femenino de Arte Actual (1963) cuando Gal fue invitada de honor (Faxedas, Fontbona y Mayayo, 2019) o en las diferentes ediciones del Concurso Pintoras de Guipúzcoa donde la artista fue siempre parte del jurado (ver Fig. 9).

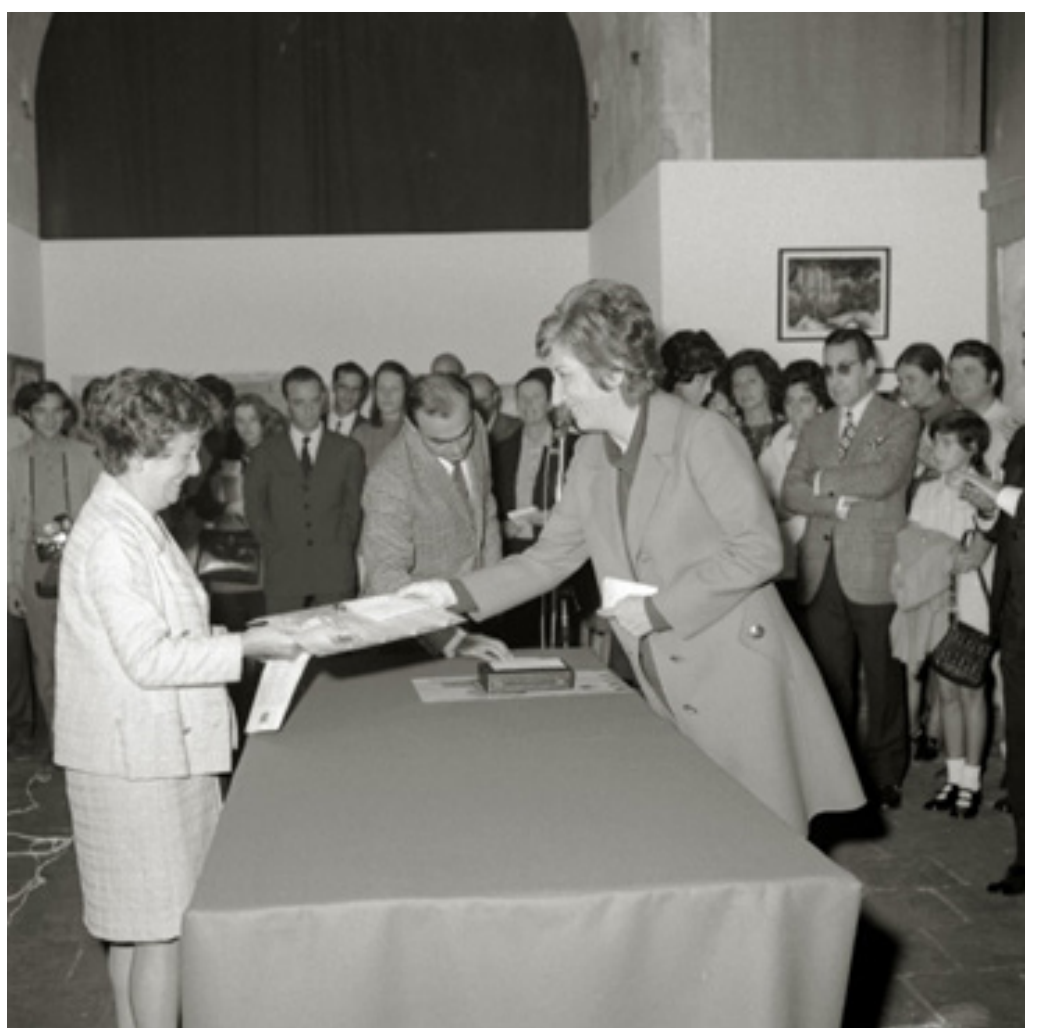

Figura 9. Acto de entrega de premios del concurso “Pintoras de Guipúzcoa". Hacia 1969. Kutxateka. Kutxa Fundazioa. 


\section{REFERENCIAS}

Aguiriano, M. (Com.) (2001). Menchu Gal: Los Menchu Gal de Menchu Gal. San Sebastián: Koldo Mitxelena Kulturunea.

Butler, J. (2002). Cuerpos que importan. Sobre los límites materiales y discursivos del "sexo". Buenos Aires: Paidós.

Cabañas Bravo, M. (2005). Delhy Tejero, una imaginación ensimismada en las décadas centrales del siglo XX. En E. Alaminos. (Com.), Delhy Tejero, 1904-1968. Ciento once dibujos (pp.27-54). Madrid: MMACM.

Cabañas, M. (1996). La política artística del franquismo: el hito de la Bienal Hispano-Americana de arte. Madrid: Consejo Superior de Investigaciones Científicas, CSIC.

Capdevila-Argüelles, N. (2013). Artistas y precursoras. Un siglo de autoras Roësset. Madrid: Editorial horas y HORAS.

Carabias Álvaro, M. (2010). Mujeres modernas de Falange, 19381940: Y revista para la mujer. Córdoba: Fundación Provincial de Artes Plásticas "Rafael Boti".

Chadwick, W. (1985). Women Artist and the Surrealist Movement. New York: Thames and Hudson.

Clarke, M. (2005). Critical Voices. Women and Art Criticism in Britain, 1880-1905. Aldershot: Ashgate.

De Diego, E. (2018). El andrógino sexuado. Eternos ideales, nuevas estrategias de género. Madrid: La Balsa de la Medusa (año de publicación del libro original, 1992).

Díaz Sánchez, J. (1998). La "oficialización" de la vanguardia artística en la postguerra española: (el informalismo en la crítica de arte y los grandes relatos). Cuenca: Universidad de Castilla-La Mancha.

Díaz Sánchez, J. (2013). La idea de arte abstracto en la España de Franco. Madrid: Ediciones Cátedra.

Faxedas, M. L., Fontbona, I., y Mayayo, P. (2019). Se Rendre Visible dans l'Espagne de Franco: le Salón Femenino de Arte Actual (1962-1971).Artl@s Bulletin, 8(1), 226-235. Recuperado de https://docs.lib.purdue.edu/artlas/vol8/iss1/15/ 
Foucher Zarmanian, C. (2015). Les femmes artistes sous presse. Les créatrices vues par les femmes critiques d'art dans la presse féminine et féministe en France autour de 1900. Sociétés \& Représentations, (40), 111-127. Recuperado de https://www.cairn.info/revue-societes-et-representations-20152-page-111.htm\#

Fuentes Vega, A. (2011). Franquismo y exportación cultural. El caso de la Exposición de Arte Español en Buenos Aires, 1947. Iberoamericana. América Latina, España, Portugal: Ensayos sobre letras, historia y sociedad, 11(44), 25-44. http://dx.doi.org/10.18441/ibam.11.2011.44.25-45

Gaitán Salinas, C. (2019). Las artistas del exilio republicano español. El refugio latinoamericano. Madrid: Ediciones Cátedra.

García Soriano, M. (2009). Lo femenino en relación al estilo y los temas tratados por las artistas plásticas de posguerra. España 1939-1957. En C. Giménez Navarro y C. Lomba Serrano. (Ed.), El arte del siglo XX (pp.325-338). Zaragoza: Universidad de Zaragoza.

Haskell, M. (2016/1974). From Reverence to Rape: The Treatment of Women in the Movies. Third Edition. Chicago: The University of Chicago Press.

Irigaray, L. (2003). Any Theory of the "Subject" has Always Been Appropriated by the "Masculine". In A. Jones. (Ed.), The Feminism and Visual Culture Reader (pp.119-127). London: Routledge.

Jiménez Blanco, M. D. (2016). Campo cerrado. Arte y poder en la posguerra española. 1939-1953. En M. D. Jiménez Blanco. (Coord.), Campo cerrado. Arte y poder en la posguerra española. 1939-1953 (pp.22-40). Madrid: Museo Nacional Centro de Arte Reina Sofía.

Jones, A. (2003). Introduction. In A. Jones. (Ed), The Feminism and Visual Cultural Reader (pp.1-7). London: Routledge.

Labanyi, J. (2002). Historia y mujer en el cine del primer franquismo. Secuencias. Revista de Historia del cine, 15, 42-59.

Lekuona Mariscal, A. (2020). La historiografía del arte del País Vasco. Una revisión feminista del siglo XX. Historia Actual Online, (51), 141-152. https://doi.org/10.36132/hao.vi51.1859

Lomba Serrano, C. (2018). Marisa Roësset, en la frontera (1924- 
1939). Archivo español de arte, 91(362), 143-158.

https://doi.org/10.3989/aearte.2018.10

Manterola, I. (2017). Maite ditut maite. Transmisioa XX. mendeko Euskal Herriko artean, Andoain: EDO! Argitaletxea.

Marzo, J. L. y Mayayo, P. (2015). Arte en España (1939-2015).

Ideas, prácticas, políticas. Madrid: Ediciones Cátedra.

Mayayo, P. (2003). Historias de mujeres, historias del arte.

Madrid: Ediciones Cátedra.

Mayayo, P. (2008). Frida Kahlo. Contra el mito. Madrid: Ediciones Cátedra.

Mayayo, P. (2009). ¿Por qué no ha habido (grandes) artistas feministas en España? Apuntes sobre una historia en busca de autor(a). En X. Arakistain y L. Méndez. (Coord.), Producciones artísticas y teoría feminista del arte: nuevos debates I (pp.112121). Vitoria-Gasteiz: Ayuntamiento de Vitoria-Gasteiz; Centro Cultural Montehermoso.

Mayayo, P. (2017). Maruja Mallo: el retrato fotográfico y la "invención de sí" en la vanguardia española. Modos, 1(1), 70-89. https://doi.org/10.24978/mod.v1i1.730

Muñoz López, P. (2003). Mujeres españolas en las artes plásticas. Madrid: Síntesis.

Muñoz López, P. (2006). Mujeres en la producción artística española del siglo XX. Cuadernos de Historia Contemporánea, (28), 97-117. Recuperado de https://revistas.ucm.es/index.php/ CHCO/article/view CHCO0606110097A

Muñoz Ruiz, Mạ C. (2003). La representación de la imagen de las mujeres en el franquismo a través de la prensa femenina, 1955-1970. En P. Amador Carretero y R. Ruiz Franco. (Eds.), Representación, construcción e interpretación de la imagen visual de las mujeres (X Coloquio Internacional de la AEIHM) (pp.405422). Madrid: Archiviana.

Muñoz Ruiz, Ma C. (2006). Modelos femeninos en la prensa para mujeres. En G. Gómez-Ferrer Morant, G. Cano, D. Barrancos y A. Lavrin. (Coords.), Historia de las mujeres en España y América Latina. Del siglo XX a los umbrales del XXI (pp.277-298). Madrid: Ediciones Cátedra.

Murga, I. (2015). Muros para pintar: Las artistas y la Residencia 
de Señoritas. En M. Márquez Padorno y A. de la Cueva.

(Coord.), La Residencia de Señoritas en su centenario (pp.102-

111). Madrid: Publicaciones de la Residencia de Estudiantes.

Nash, M. (2015). Vencidas, represaliadas y resistentes. Mujeres bajo el orden patriarcal franquista. En J. Casanoca Ruiz.

(Coord.), Cuarenta años con Franco (pp.191-228). Barcelona:

Crítica.

Parker, R. and Pollock, G. (2013). Old Mistresses: Women, Art and Ideology. London: IB Tauris.

Rosón, M. (2012). Contramodelo a la feminidad burguesa: construcciones visuales del poder en la Sección Femenina de Falange. En R. Osborne. (Ed.), Mujeres bajo sospecha. Memoria y sexualidad: 1930-1980 (pp.293-310). Madrid: Fundamentos.

Rosón, M. (2016). Género, memoria y cultura visual en el primer franquismo: (materiales cotidianos, más allá del arte). Madrid: Ediciones Cátedra.

Tejeda, I. (2013). Artistas españolas bajo el Franquismo. Manifestaciones artísticas y feminismos en los años sesenta y setenta. En P. Mayayo y J. V. Aliaga. (Coord.), Genealogías feministas en el arte español: 1960-2010 (pp.181-206). Madrid: This Side Up.

Zubiaur Carreño, F. (2011). Menchu Gal. Alegría del color. Madrid: Turner. 


\section{HEMEROTECA}

Alberti, J. (14 de marzo de 1961). Crónica de Madrid: la mujer y sus derechos. La Nueva España, p. 24.

Anónimo. (13 de enero de 1980). Mi pintura es vasca. ABC, p. 33.

Anónimo. (14 de febrero de 1976). Luis García Ochoa y la Escuela de Madrid. Blanco y negro, p. 92.

Anónimo. (17 de marzo de 1951). Muestra de la joven escuela madrileña. Fotos, p. 40.

Anónimo. (5 de diciembre de 1957). Presentados por la Caja de Ahorros de Asturias, cinco pintores jóvenes. La Nueva España, p. 3.

Anónimo. (5 de junio de 1954). Éxito artístico y popular de la II Bienal Hispanoamericana.

Fotos, p. 12.

Anónimo. (9 de mayo de 1948). La exposición de Bellas Artes. Proa, p. 4.

Anónimo. (junio de 1935). Noroeste. Eco, p. 10.

Anónimo. (1 de agosto de 1945). Siete pinceles y un cincel femeninos. Exposición Nacional de Bellas Artes. Fotos, pp. 36-37.

Anónimo. (13 de diciembre de 1947). Pinceles. Hay más mujeres que nunca. Fotos, p. 6.

Anónimo. (2 de mayo de 1953). Damas jóvenes de la pintura otoñal. Fotos, p. 8.

Anónimo. (7 de diciembre de 1941). De la Nacional de Bellas Artes. Fotos, pp. 5-6.

Anónimo. (junio de 1935). Noroeste. Eco, p. 10.

Azcoaga, E. (3 de diciembre de 1944). En el mundo pictórico de Olga Schacharoff. Fotos, p. 18. Báez, F. (9 de mayo de 1957). Menchu Gal: "considero que la crítica puede hacer un pintor". La Hora, p. 14.

Barberán, C. (1 de enero de 1942). La obra de la mujer en la Exposición Nacional de Bellas Artes. Fotos, pp. 54-55.

Barberan, C. (28 de febrero de 1955). Arte y Deporte. Los caballos en la pintora de la Duquesa de Najera. Fotos, p. 11.

Benson, B. (14 de mayo de 1944). Dos prestigios femeninos del arte actual. Fotos, pp. 19-20.

Coloma, M. (11 de marzo de 1945). Sarah Bernhard, en Madrid. Fotos, p. 8. 
De Andia, I. (12 de abril de 1945). Menchu Gal, expone. Diario Vasco, p. 2.

De Asensi, E. (8 de mayo de 1948). Nacional de Bellas Artes. Fotos, p. 20.

De Diego, J. (24 julio de 1948). Sola y sin dinero viaja por el mundo la pintora Isabel Pons. Fotos, p. 33.

De Ondarreta, M. (7 de agosto de 1942). Diario Vasco, p. 6.

Del Valle, A. (3 de junio de 1951). La pintura de Sofía Morales. Fotos, pp. 14-15.

Fundación Menchu Gal. (2013). Menchu Gal Euskera [Video]. Recuperado de http:// www.fundacionmenchugal.com/portfolio-items/video-documental-pintora-menchu-galeuskera/?portfoliolD=13539

López Izquierdo, R. (1 de agosto de 1939). La aportación femenina a la Exposición de Arte Sacro de Vitoria. Fotos, pp. 36-37.

Lozano, F. (28 de diciembre de 1946). Viaje rápido de Julia Minguillon. La única pintora que tiene primera medalla. Fotos, p. 26.

M.F.M. (13 de diciembre de 1947). Pintora improvisada. Fotos, p. 51.

Pombo Angulo, M. (19 de junio de 1948). Menchu Gal. La pintora femenina, la crítica y otras cosas. Fotos, p. 13.

Sampelayo, J. (20 de abril de 1954). La mujer ante el deporte. Marca. Semanario gráfico de los deportes, p. 15.

Sánchez Camargo, M. (26 de marzo de 1951). Hoja del Lunes, p. 5.

Seisdedos (21 de noviembre de 1962). Menchu Gal, que ha participado en la exposición "Pintores españoles de la realidad", presentada en la Galería Charpentier, ha sido invitada a exponer en la Galería Stibel. El Diario Vasco, p. 7.

Seisdedos, J. L. (15 de marzo de 1957). Menchu Gal nos dice que las Vascongadas no tienen todavía su pintor genuino, Diario Vasco, p. 8.

Tachín. (29 de mayo de 1954). Menchu Gal, distinguida con un importante galardón por el Jurado de Bellas Artes. Diario Vasco, p. 3. 
1. Destacamos algunos trabajos que han abordado esta misma cuestión en contextos históricos y geográficos diferentes como: Clarke (2005) o Foucher-Zarmanian (2015).

2. La selección de los materiales se ha realizado tras una rigurosa consulta en la Hemeroteca de la Biblioteca Nacional de España para la prensa nacional, y en el Centro de Documentación de Eusko Ikazkuntza para aquellas del territorio vasco. Por tanto, si bien no es posible precisar el número exacto de apariciones que tuvo Gal en la prensa, el material seleccionado según los criterios expuestos posibilita un acercamiento cualitativo en torno a cuál fue la imagen de la pintora en la prensa.

3. Por ejemplo, Cabañas (1996), Díaz Sánchez (1998), Fuentes Vega (2011) o Marzo y Mayayo (2015).

4. Véanse, Muñoz López (2003, 2006), García Soriano (2009) o Tejeda (2013).

5. Entre otros, Cabañas Bravo (2005), Capdevila-Argüelles (2013), Murga (2015), Lomba (2018) o Gaitán Salinas (2019).

6. Desde 2010, la gestión del legado de la artista corre a cargo de la Fundación Menchu Gal, lo que ha propiciado un aumento significativo en la cantidad de exposiciones y textos de

7. catálogos de carácter divulgativo en torno a la pintora. Entre otros destacamos los trabajos de Aguiriano (2001), Zubiaur (2011) y Manterola (2017).

8. La familia acomodada se inscribiría a favor del nacionalismo vasco, de ahí que su padre, Modesto Gal, decidiera que toda la familia se trasladara al país vecino. Sin embargo, esta tendencia política no parece que fuera de gran peso, ya que la familia volvió al acabar la guerra.

9. Encontramos esta misma estrategia en los diferentes reportajes de la época como: Anónimo (1941), Barberán (1942), Benson (1944), Azcoaga (1944), Coloma (1945), Anónimo (1945), Lozano (1946), De Diego (1948) o Anónimo (1953), entre otros.

10. Ver, por ejemplo, los trabajos de Patricia Mayayo (2008 y 2017) en torno a las autorrepresentaciones de Frida Kahlo y Maruja Mallo.

11. Véanse: López (1939), Anónimo (1942), M.F.M (1947), De Asensi (1948), Barberan (1955), Del Valle (1951).

12. Por ejemplo, "Las mujeres pueden ser tan artistas como los hombres lo que sucede es que la mayoría de ellas solo tienen como meta el matrimonio" (Seisdedos, 1957).

13. Bajo el nombre "Escuela de Madrid" presentaron obra los siguientes nombres: Redondela, Álvaro Delgado, Juan Guillermo, Novillo, Ochoa, Menchu Gal y Gregorio (Sánchez Camargo, 1951). 
14. Con el paso de los años, Delhy Tejero y Juana Faure se unirían al colectivo (Muñoz López, 2003, p.235).

15. En las entrevistas de estos años y también en las futuras es una constante la referencia al pintor español como la persona que le abrió el camino a Menchu Gal.

16. La apariencia física y el modelo de mujer infantilizada y ausente del mundo serio, tomaba como fuente de influencia el cine de comedia y entretenimiento norteamericano (Haskell, 2016, pp.231-275).

17. "Menchu Gal es una mujer alta, muy identificada con la raza de su tierra" (Báez, 1957).

18. “-¿Cree usted que la mujer puede llegar a lo genial? -Exactamente igual que el hombre -responde con resolución” (Báez, 1957).

19. La mayor parte de las referencias en la prensa hacía la obra de Menchu Gal eran positivas. Ver: De Andia (1945), Anónimo (1948), Tachín (1954), Anónimo (1954), Báez, (1957), Anónimo (1957) y Seisdedos (1957).

20. "Yo vine a Madrid en el año 1946 para luchar por mi pintura y por mi independencia; la lucha, puede creerme, ha sido dura; pero he conseguido gran parte de lo que me proponía y, desde luego, vivir de mi pintura" (Seisdedos, 1957).

21. Comola Exposición de Arte Español Contemporáneo en el Museo de Bellas Artes de Buenos Aires (1947), XXV Bienal Internacional de Venecia (1950), I Bienal Hispanoamericana de Arte (1951), II Bienal Hispanoamericana de arte (1954) y la III Bienal Hispanoamericana de Arte (1955).

22. Críticas como: "Fuerza aparentemente viril, pero, sin embargo, muy femenina" (Anónimo, 1976).

23. "[mi arte] no es una pintura social, ni he hecho tipismo, sin embargo, mi pintura es vasca porque me siento profundamente vasca" (Anónimo, 1980).

24. "-Como atisbo anecdótico te diré que el propietario de la Galería, cuando quiso entrar en negociaciones conmigo, preguntó por el 'pintor Gal'. Creía que yo era un hombre". -Seguramente por el vigor que tienen los cuadros de la pintora (Seisdedos, 1962). 